\title{
Design and process simulation on power device IGBT
}

\author{
ZHANG Hao-dong $^{1,2, a}$, LI Miao ${ }^{1, b}$, ZHANG Jian $^{1,3, c}$, ZHENG Shou-guo $^{1, \mathrm{~d}}$, HU \\ Lan $^{2, e}$, ZHU Qin-qin ${ }^{2, f}$, YUAN Yuan ${ }^{1, g}$ \\ ${ }^{1}$ Hefei Institutes of Physical Science, Chinese Academy of Sciences, China \\ ${ }^{2}$ Army Officer Academy of PLA, China \\ ${ }^{3}$ China Sciences Intelligent Agriculture Development Co.LTD of WuXi, China

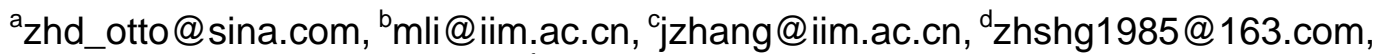 \\ e308984545@qq.com, ${ }^{\mathrm{f}}$ ahqinqin@126.com, ${ }^{\mathrm{g}}$ aahhfyy@gmail.com
}

Keywords: IGBT; Breakdown voltage; ON-resistance; TCAD

\begin{abstract}
An igbt cell structure based on semiconductor physics were designed. The process parameters of the high-voltage igbt have been calculated and adjusted. Using the optimal device's dimensions, the doping concentration was analyzed systematically. Additionally, a simulating model of igbt was compiled based on sentaurus process. According to this model simulation, an optimized device parameters' design was further determined. Finally, the device drain-source breakdown voltage has satisfied a standard value of $1450 \mathrm{v}$.whereas its threshold voltage is $4.2 \mathrm{v}$, which is in the prerequisite range of $3 \sim 5 \mathrm{v}$.
\end{abstract}

\section{Introduction}

With the rapid development of power electronics technology, high voltage Insulate Gate Bipolar Transistor (IGBT) is becoming an issue of increasing interests. To our knowledge, both the design and manufacture of TGBT are in the starting stage ${ }^{[1]}$. The purpose of this paper is to design and simulate IGBT power device model, and to find the best structure through Computer simulation and analysis.

\section{Structure design of IGBT}

The Insulated Gate Bipolar Transistor (IGBT) is a merged MOS-bipolar device which adds a p-n junction to the current path of the DMOS device in order to reduce the resistivity of the lightly doped epitaxial region during the on-state through conductivity modulation ${ }^{[2]}$. The device is fabricated on a heavily doped p-type substrate which has a lightly doped n-type epitaxial layer grown on top. However, as electrons flow across the $p-n$ junction into the $p+$ drain, holes are injected back into the n-type epi region in such concentrations that the resistivity of this lightly doped region is substantially reduced. In addition, the injected holes diffuse across the wide epitaxial region and are collected by the $\mathrm{p}+$ source diffusion through transistor action ${ }^{[3]}$. Thus, in addition to reducing the internal resistance of the DMOS device and allowing for much greater electron current to flow, adding the $\mathrm{p}-\mathrm{n}$ junction causes hole current to flow through the device during the on-state, which adds to the total drain current. In this way, the IGBT achieves conduction losses that compare well with other bipolar devices ${ }^{[4]}$.

\section{Design of $\mathrm{N}$ - drift region}

The voltage handling capability of IGBT structure is given by the breakdown voltage $\left(\mathrm{V}_{\mathrm{B}}\right)$ of the P-body/N-junction, that is strongly dependent on the thickness $\left(\mathrm{W}_{\mathrm{epi}}\right)$ and the doping of the epitaxial layer $\left(\mathrm{N}_{\text {epi }}\right)^{[5]}$. According to equation (1) and (2), the optimal parameters are calculated: the $\mathrm{n}$-base doping concentration is $3.05 \times 10^{13} \mathrm{~cm}^{-3}$, the thickness is about $101.7 \mu \mathrm{m}$. Taking into account the final process error, the n-base doping concentration is $3 \times 10^{13} \mathrm{~cm}^{-3}$, thickness is $100 \mu \mathrm{m}$.

$$
\begin{aligned}
& V_{B}=2.336 \times 10^{13} N_{e p i}^{-3 / 4} \\
& V_{B}=9.186 \times 10^{4} W_{e p i}^{6 / 7}
\end{aligned}
$$




\section{Design of P-well}

$\mathrm{R}_{\mathrm{b}}$ can be reduced through increasing the $\mathrm{p}$-well junction depth and concentration, but the $\mathrm{p}$ region doping can not be increased indefinitely, or it will over compensate the emitter region. Consequently, P region doping concentration is set to $1 \times 10^{19} \mathrm{~cm}^{-3}$, the junction depth is set to $6 \mu \mathrm{m}$.

\section{Design of $\mathbf{p}+$ collector area parameter}

The simulation results know that, with $\mathrm{p}+$ collector area doping concentration increased, saturated pressure drop is reduced, turn-off time increases. In order to meet the turn-off time of design index, and make the saturated pressure drop low as far as possible, finally $p+$ collector area concentration is selected as $1 * 10^{19} \mathrm{~cm}^{-3}$. To sum up, the size of IGBT device is finally determined shown in table 1.

Table.1 the parameters of IGBT structure

\begin{tabular}{|c|c|}
\hline parameter & size $(\boldsymbol{\mu m})$ \\
\hline channel length & 2 \\
\hline gate oxide thickness & 0.05 \\
\hline $\mathrm{n}+$ source width & 7 \\
\hline $\mathrm{p}$ well width & 11 \\
\hline $\mathrm{p}+$ well width & 6 \\
\hline substrate thickness & 150 \\
\hline buffer layer thickness & 15 \\
\hline $\mathrm{n}$ - drift layer thickness & 100 \\
\hline
\end{tabular}

\section{The process design of IGBT}

According to the above designed IGBT structure, referring to current IGBT mainstream plane process, after many comparisons of technological design simulation, the process of technological design is shown in figure 1.
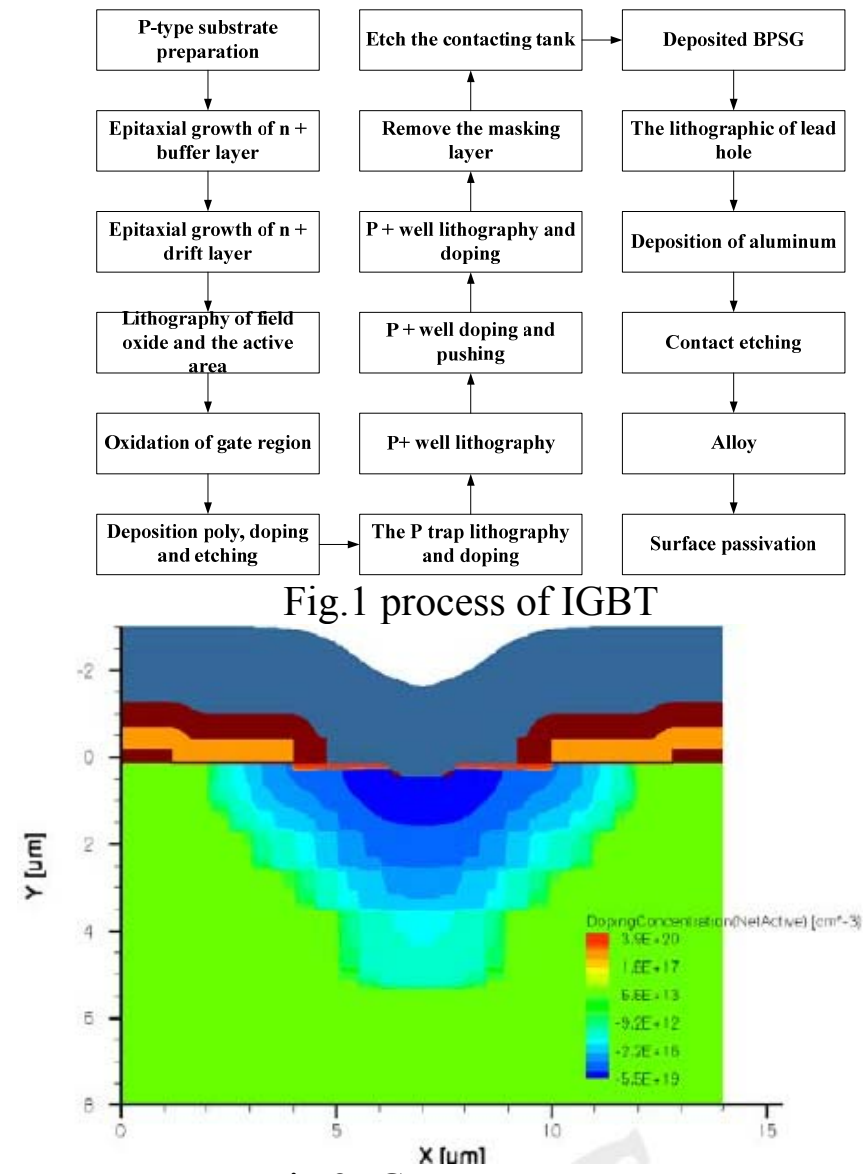

Fig.2 IGBT structure

During the whole process, the most noteworthy is "ion implantation", besides choosing the impurity according to the requirements of the PN junction, implanting energy according to the 
depth of the junction, but also further considering the ion implantation masking layer selection and the angle of injection. The device result diagram of process simulation is as follows:

\section{IGBT device simulation}

\section{Static characteristic simulation}

After the applying positive bias voltage to the device collector, scanning the grid voltage of the device grid, extracting the change curve of the collector current, we get the device transfer characteristic curve as shown in figure 3 below. When grid voltage is less than $4.3 \mathrm{~V}$, collector current is small, the conductive channel has not been formed, and device is in cut-off state. When the grid voltage is more than $4.3 \mathrm{~V}$, collector current appears linear growth, and increases rapidly. From the simulation results, we know IGBT threshold voltage is $4.2 \mathrm{~V}$. Figure 4 describes the on-resistance changes with the collector voltage when devices work. IGBT turns on, the collector area at the back injects a large number of minority carriers (hole) to the high resistance base area, and thus modulates the conductivity of the high resistance base area, which produces the so-called conductivity modulation effect, so the on-resistance of the device drops rapidly.

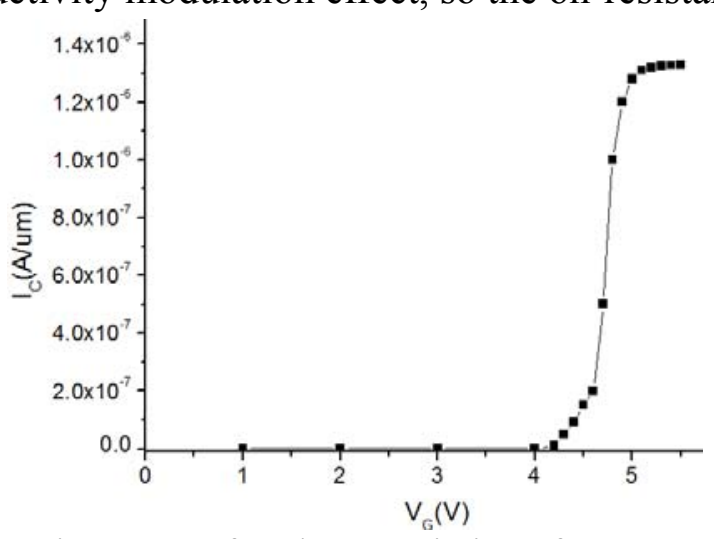

Fig.3 Transfer characteristics of IGBT

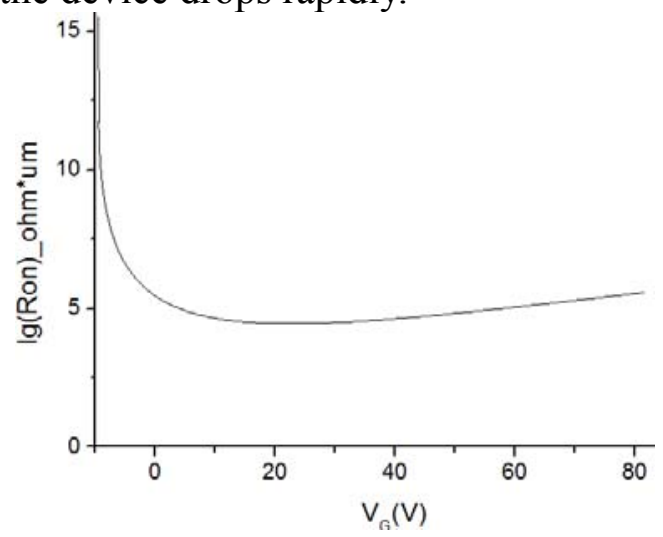

Fig.4 On-resistance

\section{Breakdown characteristic simulation}

A greater value resistance is needed to pick up the collector when analyzes the breakdown characteristic because before the breakdown is happened in IGBT device, the collector current is small, basically constant. At this time, it will be work well through the voltage control scanning. But after the breakdown, a small collector voltage change will lead to a significant increase of the collector current, at this time, the voltage control scanning is difficult to convergence, flow control scanning is a must. Turn from the voltage control scanning before the breakdown to flow control scanning after the breakdown, the most effective method is using an appropriate resistance in the collector. Resistance must be large enough, guarantee most of the voltage drop in the resistance after the breakdown.

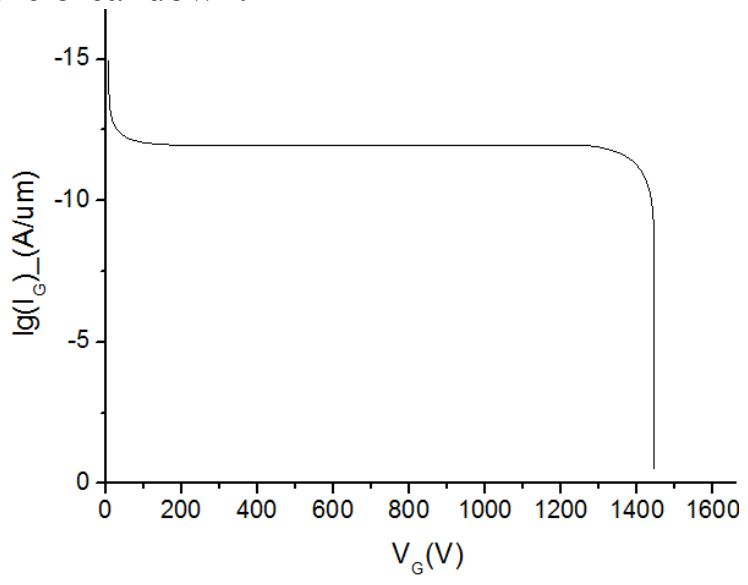

Fig.5 Breakdown characteristics

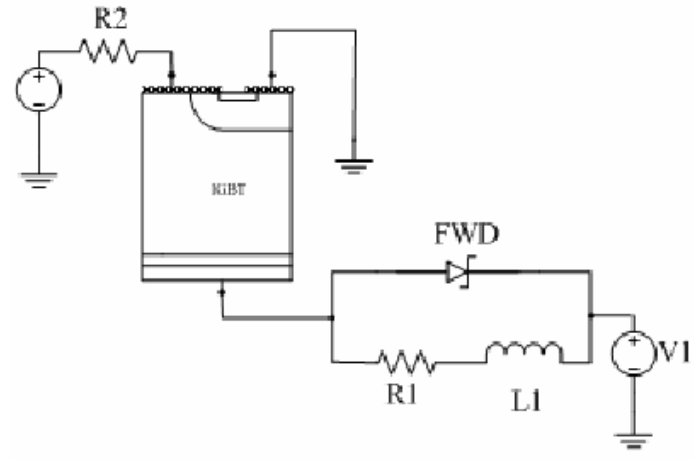

Fig.6 Test circuit

While simulation, ground the grid and emitter, scan the collector voltage from $0 \mathrm{~V}$ to $2000 \mathrm{~V}$, extract collector current change curve, as shown in figure 5. When the VGE is $0 \mathrm{~V}$, collector-emitter 
voltage is less than $1450 \mathrm{~V}$, IGBT device is in a forward blocking state, only small leakage current between collector and emitter. When collector-emitter voltage is more than $1450 \mathrm{~V}$, the collector current of the device suddenly increases, and the corresponding collector voltage at this time is the positive breakdown voltage of the collector, which is about $1450 \mathrm{~V}$. According to the simulation result, when breakdown voltage is slightly less than $1500 \mathrm{~V}$, the design requirements are basically met.

\section{Dynamic characteristics simulation}

IGBT device is mainly used for switch, and the study of switch characteristic study is an important part of the device research content. This paper uses the external extraction circuit as shown in figure 6 to test the device switch characteristics. Due to the multiple devices contained in the circuit, therefore we can only use hybrid simulation model to simulate the IGBT switch characteristics. Turn the collector voltage to positive bias, use square signal of $20 \mathrm{KHZ}$ frequency to scan grid voltage, extract collector current and voltage variation curve, and get the simulation results as shown in figure 7 and figure 8.

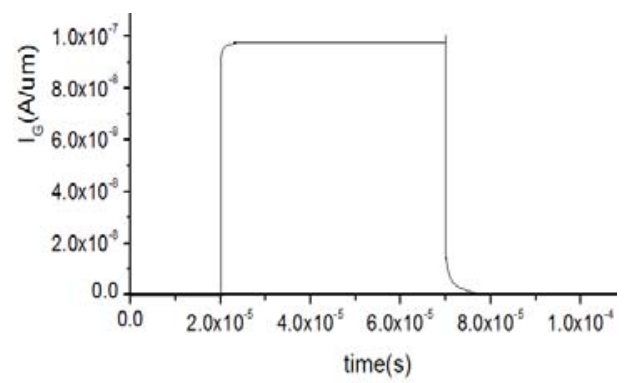

Fig.7 Collector current in the IGBT switch process

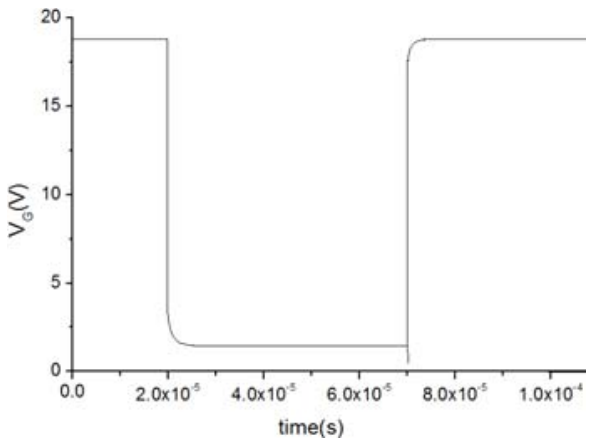

Fig. 8 Collector voltage in the IGBT switch process

From the graph, we can conclude that when grid voltage increases from $0 \mathrm{~V}$ to $5 \mathrm{~V}$, the collector current increases rapidly, and quickly achieves the stable value, the turn-on time of the device is very short. When grid voltage decreases from $5 \mathrm{~V}$ to $0 \mathrm{~V}$, the collector current decreases rapidly to a certain value and then slows down, the current is the so-called trailing current. From the simulation results, we know the turn-off time of the device is about 1.8 us, which meets the requirement of the design index.

\section{Conclusion}

This paper analyzes the basic structure of IGBT and its working principle, optimizes the design of the IGBT structure, makes use of S_process and analyzes its process design and simulation, and finally tests the designed IGBT device transfer property, on-resistance, output characteristics, dynamic characteristics through the device simulation, providing theoretical foundation for the design and production of IGBT.

\section{References}

[1] Yang Hong-qiang, Chen Xing-bi. A High Speed IGBT Based on Dynamic Controlled Anode-Short. Chinese Journal of Semiconductors. 2002, 23(4):347 350.

[2] H.P.E. Xu; O.P. Trescases; I.-S.M. Sun, D. Lee. Design of a rugged 60 V IGBT transistor. IET Circuits Devices Syst [J], 2007, PP327-331.

[3] Philips Semiconductor Applications AN10273_1.Power MOSFET single-shot and repetitive avalanche ruggedness ratin. Philips Semiconductors, 2003.

[4] S. Kyoung, J. S. Lee, et al. A Novel Trench IGBT with a Deep P+Layer Bebeaththe Trench Emitter. IEEE Trans. on Electron Device Letters. 2009, 30(1): 82 84.

[5] J. S. Lee, H. H. Shin, et al. An improvement of the Breakdown Voltage Characteristic of Trench Gate IGBTs by Using a Shielding Layer. IWPSD, Mumbai, 2007:799 802. 